\title{
An Overview of Bidirectional DC-DC Converter Topologies and Control Strategies for Interfacing Energy Storage Systems in Microgrids
}

\author{
Nisha Kondrath \\ Department of Electrical \& Computer Engineering, Villanova University, Villanova 19085, USA
}

\begin{abstract}
A microgrid is defined as a local electric power distribution system with diverse DG (distributed generation) units, energy storage systems, and loads, which can operate as a part of the distribution system or when needed can operate in an islanded mode. Energy storage systems play a key role in improving security, stability, and power quality of the microgrid. During grid-connected mode, these storage units are charged from various DG sources as well as the main grid. During islanded mode, DG sources along with the storage units need to supply the load. Power electronic interfaces between the microgrid buses and the storage units should be able to detect the mode of operation, allow seamless transition between the modes, and allow power flow in both directions, while maintaining stability and power quality. An overview of bidirectional converter topologies relevant to microgrid energy storage application and their control strategies will be presented in this paper.
\end{abstract}

Key words: Microgrid, energy-storage systems, power electronic interface, bidirectional converters.

\section{Introduction}

Microgrid is defined as a network of local electric power sources, energy storage units, power conversion systems, and communication systems which operate in parallel with the utility grid (grid-connected mode) or independently as a stand-alone system (islanded mode) to supply a network of local loads [1-16]. Fig. 1 shows a typical microgrid setup. Depending on the number or different types of DERs (distributed energy resources), DESs (distributed energy sources) and distributed loads, power electronic converters are used as interfaces to connect DERs to a DC or an AC bus and the microgrid can be classified as a DC microgrid, an AC microgrid, or a hybrid microgrid. During normal operation, microgrid operates in the grid-connected mode. In the grid-connected mode, the utility grid determines the voltage and frequency of the microgrid and supports any deficit energy; and any excess energy

Corresponding author: Nisha Kondrath, Ph.D., assistant professor, research fields: power electronics, DC-DC converters, DC-AC inverters and high-frequency magnetics. from the microgrid is supplied to the power grid. In case of utility grid failure, the microgrid disconnects at the PCC (point of common coupling) and operates in the islanded mode. During the islanded mode, DERs and DESs are responsible for supplying the loads and balancing the power in the microgrid.

Having reliable energy storage systems is critical in improving the stability, robustness, and power quality of the microgrid. Energy storage systems or batteries can be connected to the microgrid independently or work in conjunction with a distributed energy resource. Bidirectional DC-DC power converters (BDC) play a key role in interfacing DES (distributed energy storage) units with the microgrid, irrespective of the microgrid type. During the grid-connected mode, the utility grid as well as the DERs meets the load demand. During this time, power flows from the DC bus to charge the energy storage device. When the microgrid operates in the islanded mode, the load demand must be met and balanced by the DERs and the energy storage devices. When the power generated by DERs is greater than the load, the BDC connected to the storage device will 


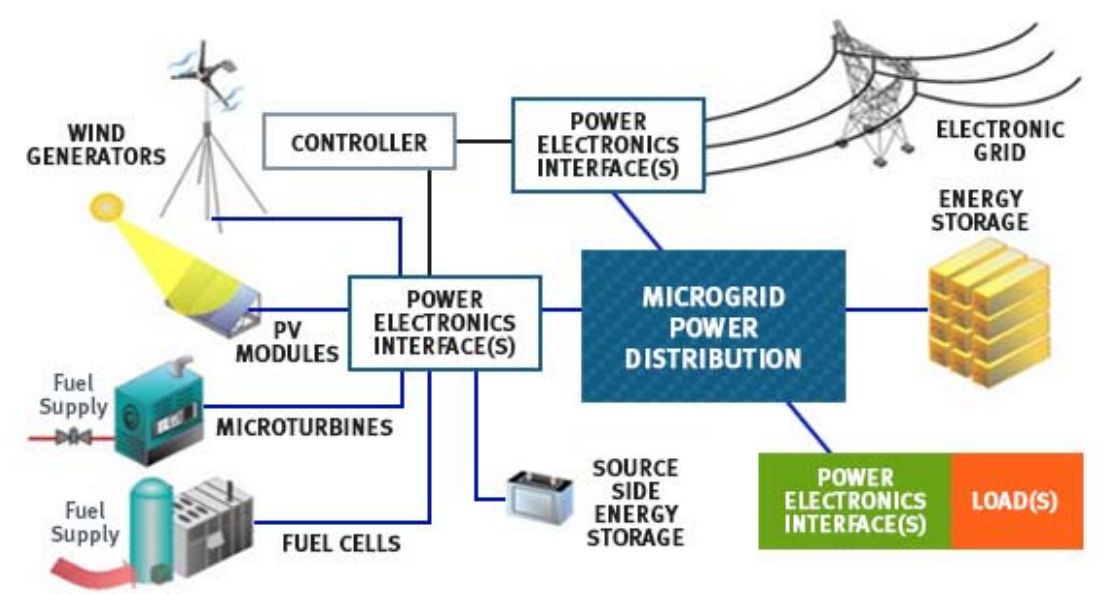

Fig. 1 A typical microgrid [1].

transfer power to charge the storage unit. When power generated by DERs is not enough to supply the loads, the BDC will transfer the stored energy from the storage unit to the DC bus.

Thus, the bidirectional DC-DC converter interface connecting DESs to the microgrid has two main objectives: (1) to control the direction and amount of power to and from the storage device and (2) to control the DC link. Batteries are integral to maintaining the stability and resiliency of the microgrid. However, the stability and response time of the system is dependent on the dynamic characteristics and control of the bidirectional converter. Power electronic interfaces between the microgrid buses and the storage units should be able to detect the mode of operation, allow seamless transition between the modes, and allow power flow in both directions, while maintaining stability and power quality. An overview of bidirectional converter topologies for interfacing various energy storage units to microgrid and their control strategies will be presented in this paper. Different topologies suitable for different load requirements will be reviewed along with their steady-state characteristics. In addition, characteristics of various control systems will be discussed.

\section{Bidirectional DC-DC Converter Topologies}

DES units in microgrids can be batteries connected independently to the microgrid, batteries working in conjunction with DERs, or batteries as part of a hybrid storage system [2-4]. Bidirectional power converters play a key role in interfacing DES units to the microgrid. These converters transfer power from the DC bus to the DES unit during normal mode of operation and transfer power from the DES unit to the DC bus when DERs and/or utility grid are not available. To facilitate bidirectional power flow capability, the converters need bidirectional power devices as switches. Controllable semiconductor devices with anti-parallel diodes will provide the bidirectional capability; including positive and negative current flow as well as positive and negative voltage blocking capabilities. Ref. [2] presented a review of non-isolated bidirectional DC-DC converters, which is especially attractive in applications where size and weight are the main concerns. Basic non-isolated converters, converters with coupled inductors, and interleaved converters were reviewed with focus on topologies that provide constant current to the battery, thus prolonging the battery life. Selected non-isolated, isolated, and interleaved bidirectional DC-DC converter topologies relevant to interfacing various energy storage units to the microgrid will be reviewed in this section.

\section{A. Bidirectional Buck-Boost DC-DC Converter}

Fig. 2 shows a bidirectional buck-boost DC-DC 
converter that can be used to interface a battery to the microgrid [3]. The combination of transistor $\mathrm{Q}_{1}$ and antiparallel diode $\mathrm{D}_{1}$ forms the switch $\mathrm{S}_{1}$ as well as the combination of transistor $\mathrm{Q}_{2}$ and antiparallel diode $\mathrm{D}_{2}$ forms the switch $S_{2}$. This topology is able to step up or step down the voltage with power flow in both directions. During the charging mode, the converter operates as a buck converter and charges the battery from the DC bus at a voltage $V_{D C}$ with a conversion ratio of

$$
\frac{V_{B a t t e r y}}{V_{D C}}=\frac{D_{2}}{1-D_{2}}
$$

where, $D_{2}$ is the duty cycle of $S_{2}$. During the discharging mode, the converter operates as a buck or boost converter to transfer power from the battery to the DC bus, depending on overvoltage or undervoltage state of $V_{D C}$, respectively. In this mode, the DC voltage conversion ratio is given by

$$
\frac{V_{D C}}{V_{\text {Battery }}}=\frac{D_{1}}{1-D_{1}}
$$

where, $D_{1}$ is the duty cycle of the switch $\mathrm{S}_{1}$. Appropriate control algorithms will determine charging and discharging modes as well as buck and boost operating modes of the converter.

\section{B. Bidirectional Buck/Boost DC-DC Converter for Hybrid Storage Systems}

A typical set up to interface a hybrid storage system, including a battery and a super capacitor, to the microgrid is depicted in Fig. 3. Super capacitor is a typical high-power device with fast response, high output power capability, and high energy conversion efficiency. Battery is a typical high-energy device with slow response, long-time power output capability, and high energy density. A hybrid storage system is suitable for low-cost, power balance control in microgrids [4]. A bidirectional buck/boost converter is used as the power electronic interface. Both the battery and the super capacitor are connected to the low voltage side of the converter. Let $\mathrm{D}_{1}$ be the duty cycle of $S_{1}, D_{2}$ be the duty cycle of $S_{2}, D_{3}$ be the duty cycle of
$\mathrm{S}_{3}$, and $\mathrm{D}_{4}$ be the duty cycle for $\mathrm{S}_{4}$. During the charging mode, the converter operates as a buck converter and power flows from the DC bus to the storage units with a DC voltage transfer function of

$$
M_{V D C}=D_{2} \text { and } M_{V D C}=D_{4}
$$

for the battery and the super capacitor, respectively. During the discharging mode, the converter operates as a boost converter with a conversion ratio of

$$
M_{V D C}=\frac{1}{1-D_{1}} \text { and } M_{V D C}=\frac{1}{1-D_{3}}
$$

and transfer power from the battery or super capacitor to the DC bus, respectively. As the storage units have different charging and discharging characteristics and have different balancing capabilities, the converters should be able to address these requirements. Control schemes need to be employed to choose the appropriate storage unit depending on the type of disturbance or unbalance that needs to be mitigated.

\section{Bidirectional Full-Bridge DC-DC Converter}

In some cases, storage units are dedicated to provide

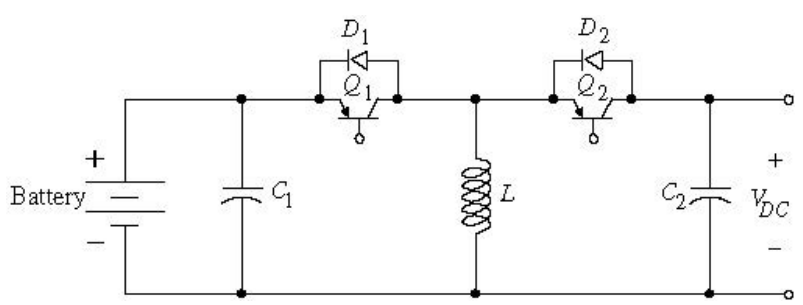

Fig. 2 Bidirectional buck-boost converter [3].

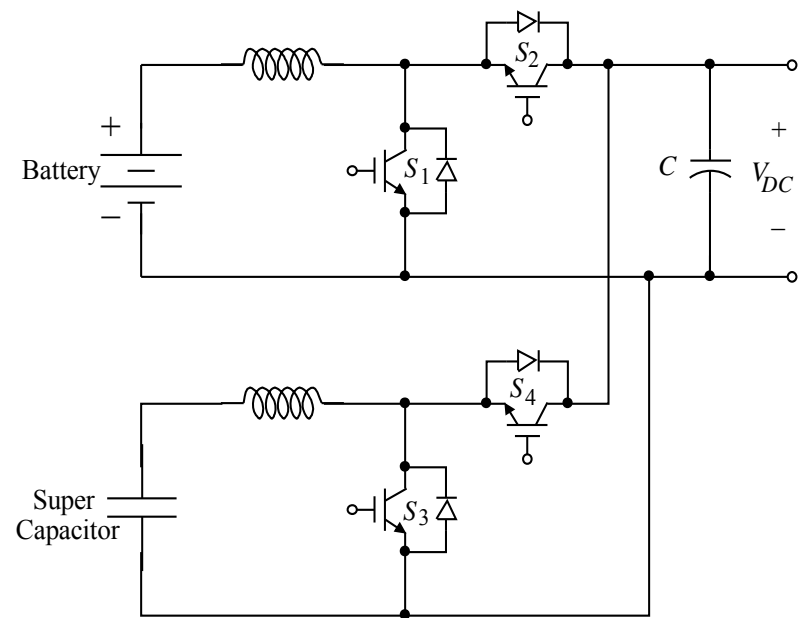

Fig. 3 Bidirectional buck-boost converter for a hybrid storage system [4]. 
power to sensitive and critical loads, where galvanic isolation is necessary. Isolated bidirectional DC-DC topologies are preferred in such situations [5-7]. Such topologies also provide high step-up or step down conversion ratios by utilizing the transformer turns ratio. A bidirectional FB (full-bridge) DC-DC converter circuit is shown in Fig. 4. The battery is usually connected to the low-voltage side of the converter. A transformer with a turns ratio of $n: 1$ provides isolation between low-voltage and high-voltage sides and extra conversion ratio if needed. The four switches $S_{1}, S_{2}, S_{3}$, and $S_{4}$ form Bridge $A$ and the four switches $S_{5}, S_{6}, S_{7}$, and $S_{8}$ form Bridge B. During the charging mode of the battery, power flows from high-voltage side to low-voltage side and the converter operates as a buck converter. At this time, Bridge $\mathrm{B}$ acts a FB inverter and Bridge $\mathrm{A}$ acts as a FB rectifier. The conversion ratio for this mode is

$$
\frac{V_{B a t t e r y}}{V_{D C}}=\frac{2 D_{2}}{n},
$$

where, $D_{2}$ is the duty cycle of the switches in Bridge A. During the discharging mode, Bridge $\mathrm{A}$ acts as a FB inverter and Bridge $\mathrm{B}$ acts a $\mathrm{FB}$ rectifier. In this case, the power flows from the battery to the DC bus and the converter operates as a boost converter with a conversion ratio of

$$
\frac{V_{D C}}{V_{\text {Battery }}}=\frac{n}{2\left(1-D_{1}\right)}
$$

where, $D_{1}$ is the duty cycle of the switches in Bridge $B$. An isolated dual active bridge converter using wide band gap GaN devices to improve converter efficiency was presented in Ref. [8].

\section{Multi-phase Interleaved Bidirectional DC-DC Converter}

Power electronic interfaces are expected to have high efficiency and high power density. In order to obtain high power density, it is a common practice to operate the converters in DCM (discontinuous conduction mode). However, this may result in very high current ripple, which may be hazardous for the battery or other storage devices. One solution to this issue is to use multi-phase interleaved DC-DC converters [9]. A three-phase interleaved bidirectional DC-DC converter is shown in Fig. 5. The DC voltage transfer functions in both modes of operation, as in traditional buck and boost converters, are given by Eqs. (3) and (4). However, by dividing the current between the three phases, current stresses as well as inductor and capacitor sizes are reduced; thereby increasing the power density. Moreover, the interleaved topology minimizes the battery current ripple; thereby improving battery life. By adding appropriate phase differences between the three phases, the total inductor current can be minimized. Soft-switching techniques were used in Ref. [9] to further reduce the switching losses and increase the converter efficiency.

\section{E. Floating Interleaved Bidirectional DC-DC Converter}

Fig. 6 shows a floating interleaved bidirectional DC-DC converter, with double non-floating positive branch and double floating negative branch [10]. This configuration enables higher efficiency, higher voltage gain, and lower current ripple compared to the

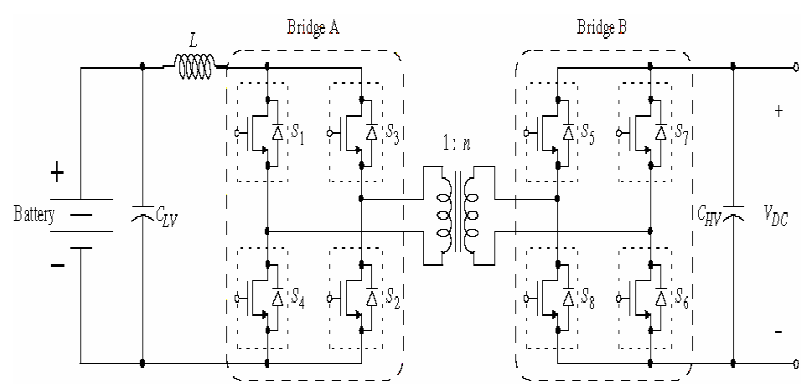

Fig. 4 Bidirectional full-bridge DC-DC converter [7].

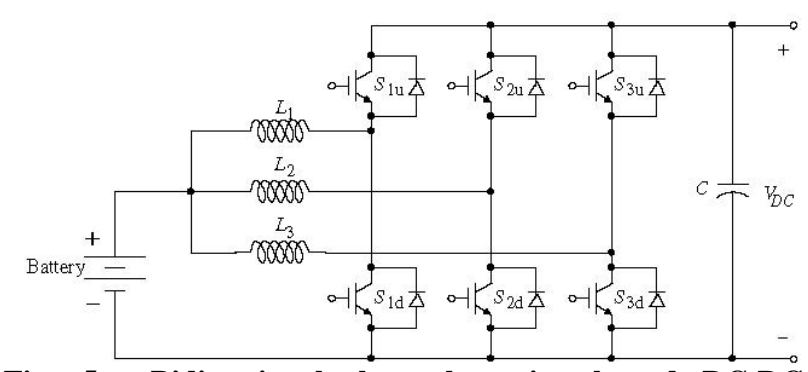

Fig. 5 Bidirectional three-phase interleaved DC-DC converter [9]. 


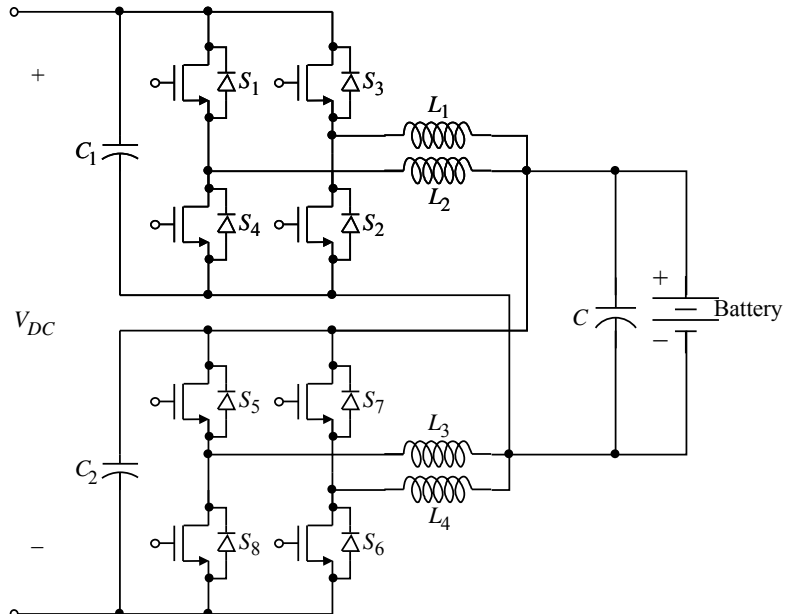

Fig. 6 Bidirectional floating interleaved DC-DC converter [10].

multi-phase interleaved converters in Section II of part D. The high voltage gain, the battery banks can be of relatively low voltage and as a result, fewer series connected battery units are needed. This improves system reliability in parallel-connected systems.

\section{Control Strategies}

While the choice of appropriate bidirectional converter topology is crucial to ensure efficient power transfer between the DC bus and the storage units, choosing the appropriate control strategy is paramount in detection of the mode of operation, controlling the direction and amount of power transfer to and from the storage unit, and ensuring seamless transition between modes; while maintaining stability and power quality. This is especially imperative in the islanded mode of operation. A review of control methods, its challenges and needs for energy storage systems in microgrids was presented in Ref. [11].

\section{A. Current-Mode Control}

As already mentioned, the bidirectional converter control is expected to maintain the DC bus voltage a constant as well as to regulate charging/discharging current. Current-mode control with two feedback loops, an inner current loop and an outer voltage loop, is a popular control method suitable in this case. Fig. 7 shows a synchronous buck converter with current-mode control [12]. The current controller controls the inductor current, which essentially is the charging/discharging current of the battery. The voltage controller controls the DC link voltage, which is the input voltage during the charging mode and the output voltage during the discharging mode.

An energy management architecture, which accommodates different modes of microgrid operation, state-of-charge of the battery as well as power levels of DERs and battery, was also presented in Ref. [12]. Current-mode control has inherent advantages such as faster response time and short-circuit protection over traditional voltage-mode control. However, it also suffers from inherent instability and sub-harmonic oscillations.

\section{B. Power Control}

In the grid-connected mode, the controller should focus on the SOC (state-of-charge) of the battery. On the other hand, during islanded mode, the microgrid stability and power quality should be the highest priority for the controller. Taking this into account, a power control algorithm, as shown in Fig. 8, was presented in Ref. [3]. From the figure, it can be seen that during the grid-connected mode, battery control is based on SOC control. During the islanded mode, fuzzy control or advanced droop control is chosen based on the amount of voltage disturbance.

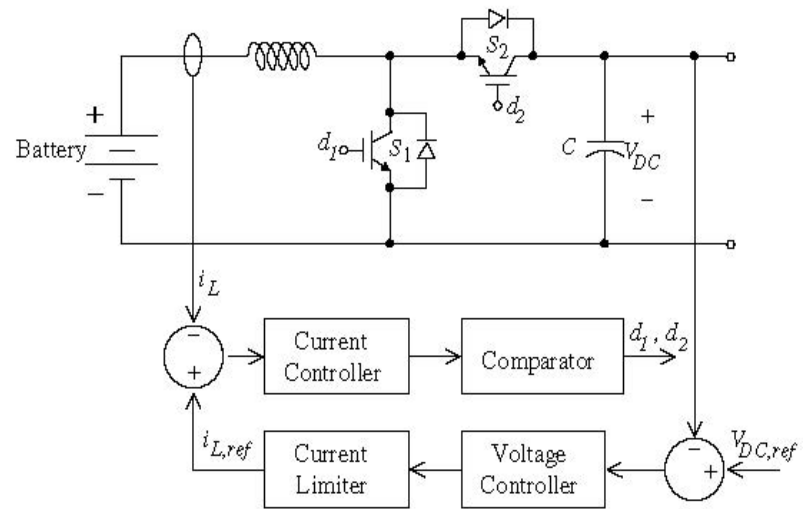

Fig. 7 Bidirectional DC-DC buck converter with current-mode control [12]. 


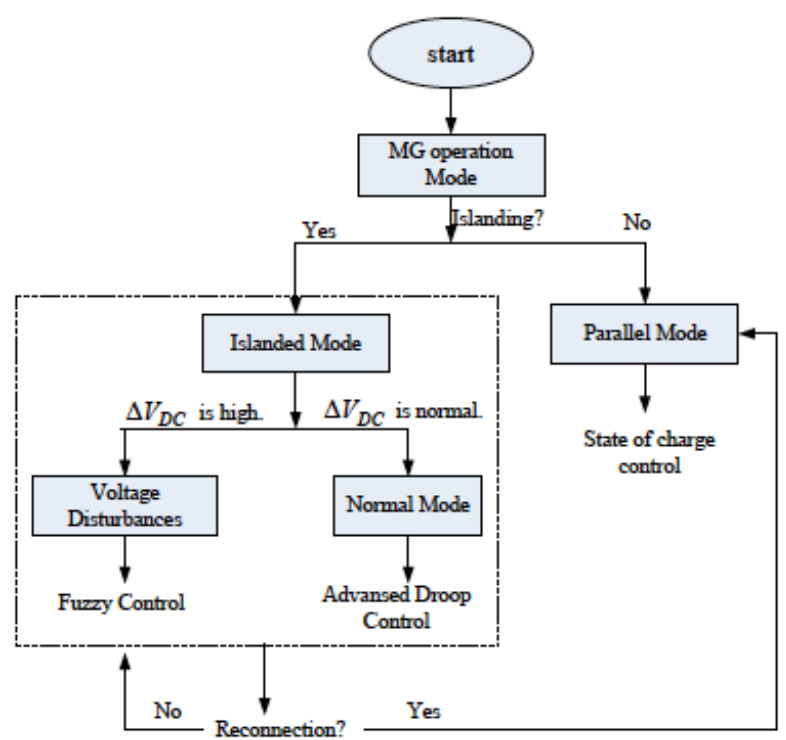

Fig. 8 Power control algorithm [3].

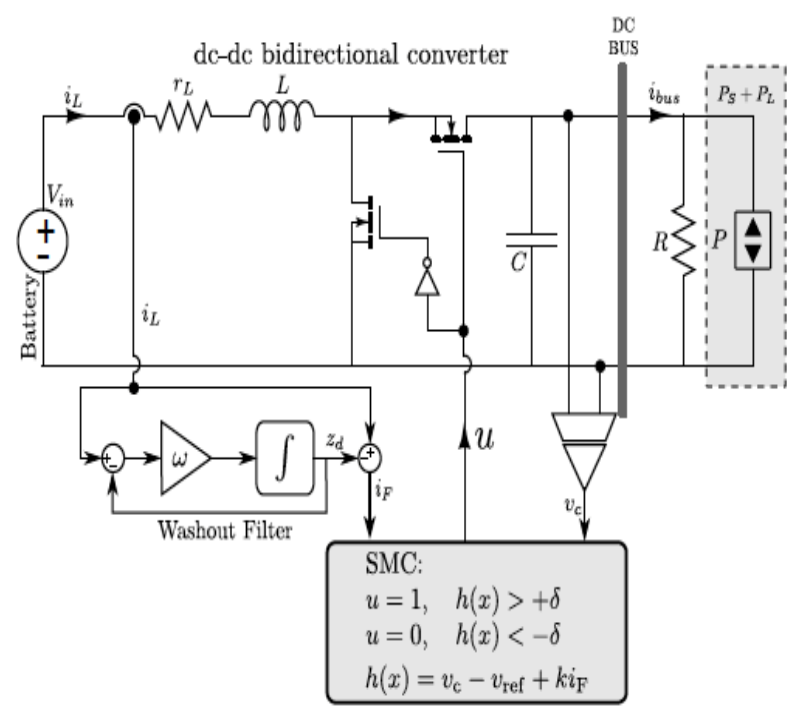

Fig. 9 Synchronous buck converter with sliding mode control including washout filter [14].

\section{Non-linear Control}

In cases where the DC bus is supplying CPLs (constant power loads) with highly non-linear characteristics, traditional lineal control schemes may not ensure the required performance. One popular method to stabilize the DC bus voltage is sliding mode control; known to be robust against system variations mode control based on a washout filter (low-pass filter) was proposed in Ref. [14] to regulate the bidirectional converter against the non-linear load characteristics. The circuit schematic is shown in Fig. 9. Control objectives included regulating the BDC output voltage ensuring robustness under variations of the load and input and minimizing the transient response during load variations during the islanded operation. In Ref. [4] sliding mode control was implemented on a DC microgrid with CPLs to handle large variations in load demand.

\section{Conclusions}

Energy storage systems play a key role in improving security, stability, and power quality of the microgrid. Power electronic interfaces between the microgrid buses and the storage units should be able to detect the charging or discharging modes as well as grid-connected or islanded modes of operation, allow seamless transition between the modes, and allow power flow in both directions, while maintaining stability and power quality.

A review of bidirectional DC-DC converter topologies relevant to microgrid energy storage, including non-isolated, isolated, and interleaved topologies has been presented. Voltage conversion ratios for each of the topology with bidirectional power flow have been presented. Non-isolated topologies are suitable for applications that require lower DC voltage transfer functions. Isolated converters are preferable where galvanic isolation is necessary. These converters are also suitable for applications that require high step-up or step-down ratios, since the turns ratio of the transformer can be utilized to improve the DC transfer function. Despite the complexity of the interleaved converters, they are more suitable for high power applications. Since the current is divided between multiple phases; the current stress on the devices and inductors, size of the passive components, and the battery current ripple can be reduced. To improve the battery life, it is preferred to have converter topologies that deliver an almost constant current to charge the battery.

While the choice of appropriate bidirectional converter topology is crucial to ensure efficient power 
transfer between the DC bus and the storage units, choosing the appropriate control strategy is paramount in maintaining the resiliency, reliability, and stability of the microgrid. These control units should be able to determine the modes of operation, determine the amount of power transfer to and from the storage units, and control the DC bus voltage. Several control strategies including current-mode control, power control, and sliding mode control have been reviewed in this paper. One main challenge in designing an effective control strategy is the lack of complete models for the bidirectional converters, especially for advanced topologies with different modes of operations.

\section{References}

[1] http://www.doosangridtech.com/faq/microgrid. Accessed June 21, 2017.

[2] Tytelmaier, K., Husev, O., Veligorskyi, O., and Yershov, R. 2016. "A Review of Non-isolated Bidirectional DC-DC Converters for Energy Storage Systems." In Proceedings of Int. Young Scientists Forum on Applied Physics and Engineering (YSF), 22-8.

[3] Sofla, M. A., and Wang, L. 2011. "Control of DC-DC Bidirectional Converters for Interfacing Batteries in Microgrids." In Proc. of IEEE Power Systems Conference and Exposition.

[4] Li-Jun, J., Guang-Yao, Y., Miao-Miao, J., Yi-Fan, C., Hai-Peng, Z., and Ke, Z. 2015. "Study of Bi-directional DC-DC Converter of Micro-grid Hybrid Energy Storage System." In Proceedings of 10th IEEE Conference on Industrial Electronics \& Applications.

[5] Kondrath, N., and Smith, N. R. 2016. "An Investigation into the Trade Space of Advanced Wide-Band Gap Semiconductor Devices in a Full-Bridge DC-DC Converter.” SAE Int. Journal on Aerospace 9 (1): 37-44.

[6] Inoue, S., and Akagi, H. 2007. "A Bidirectional DC-DC Converter for an Energy Storage System with Galvanic Isolation." IEEE Transactions on Power Electronics 22 (6): 2299-306.
[7] Kondrath, N. 2017. "Design and Evaluation of a Novel Hybrid Sic-Gan Based Bidirectional Full-Bridge DC-DC Converter." SAE Technical Paper 2017-01-2032. doi:10.4271/2017-01-2032.

[8] Xue, F., Yu, R., and Huang, A. Q. 2017. “A 98.3\% Efficient GaN Isolated Bidirectional dc-dc Converter for DC Microgrid Storage System Applications." IEEE Transactions on Industrial Electronics 64 (11): 9094-103.

[9] Zhang, J., Lai, J.-S., Kim, R.-Y., and Yu, W. 2007. "High-Power Density Design of a Soft-Switching High-Power Bidirectional DC-DC Converter." IEEE Transactions on Power Electronics 22 (4): 1145-53.

[10] Simões, M. G., Lute, C. L., Alsaleem, A. N., Brandao, D. I., and Pomilio, J. A. 2015. "Bidirectional Floating Interleaved Buck-Boost DC-DC Converter Applied to Residential PV Power Systems." In Proceedings of IEEE Power Systems Conference.

[11] Zamora, R., and Srivastava, A. K. 2014. "Controls for Microgrids with Storage: Review, Challenges, and Research Needs." Elsevier Journal for Renewable and Sustainable Energy Reviews 14 (7): 2009-18.

[12] Zamora, R., and Srivastava, A. K. 2014. "Energy Management and Control Algorithms for Integration of Energy Storage within Microgrid." In Proceedings of IEEE 23rd International Symposium on Industrial Electronics (ISIE), 1805-10.

[13] Hussainy, S. A. A., Tandon, R. G., and Kumar, S. 2012. "PWM Based Sliding Mode Control of DC-DC Converters." In Proceedings Int. Conf. on Advances in Power Conversion and Energy Technologies.

[14] Tahim, A. P. N., Pagano, D. J., and Ponce, E. 2012. "Nonlinear Control of DC-DC Bidirectional Converters in Stand-Alone DC Microgrids." In Proceedings of 51st IEEE Conference on Decision and Control.

[15] Agarwal, A., Deekshitha, K., Singh, S., and Fulwani, D. 2015. "Sliding Mode Control of a Bidirectional DC-DC Converter with Constant Power Load." In Proceedings of IEEE 1st Int. Conf. on DC Microgrids.

[16] Liu, L-Y., Tsai, M-C., Hsu, C-L., Lo, K-Y., and Chang, Y-R. 2015. "Design of a Energy Storage Converter for Microgrid Applications." In Proceedings of 4th International Conference on Renewable Energy Research and Applications. 